\title{
الواقع السياسي وتأثيره على فعالية القضاء الدستوري
}

\author{
م.م. منير حمود دخيل \\ قسم القانون العام ـ كلية القانون - جامعة ذيل فار فار ـ العراق \\ الايميل: munirhd@gmail.com
}

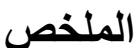

يعتبر القضاء الدستوري واحداً من الوسائل المهمة لضمان التزام السلطات العامة في الدولة بأحكام الدستور ، من خلال رقابته على دستورية القو انين، وسواء كانت هذه الرقابة قضائية أو سياسية. وتتمتع السلطة القضائية الدستورية بمكانة كبيرة بين السلطات في أغلب البلدان والأنظمة الدستورية المعاصرة. وتعدد العوامل الخارجية المؤثرة على القضاء الدستوري، ولصعوبة الإحاطة بكل تللك العو امل الخارجية المؤثرة على هذا القضاء، لذلك تخيرنا أهمها وهو تأثير الو اقع السياسي على بعض أحكامه. فالرقابة الدستورية التي هي من اختصاصهـالقضاء

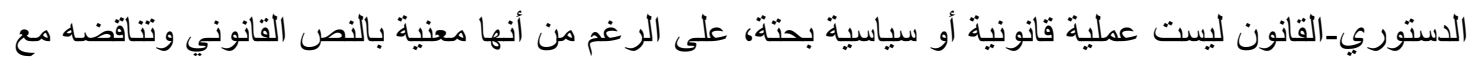
دستور. يجب أن يكون هنالك المزيد من الضمانات التي تحمي القضاء الدستوري وتجعله بعيداً عن الصر اعات السياسية، و غير قابل للانقياد من خلال الاحكام التي يصدر ها لجهة على حساب جهة أخرى. 


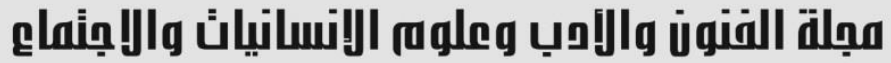

Journal of Arts, Literature, Humanities and Social Sciences

www.jalhss.com

Volume (54) July 2020

العدد (54) يوليو 2020

\section{The Political Reality and Its Impact on the Effectiveness of The Constitutional Judiciary}

\author{
Munir Hmood Dakheel \\ Public Law Dept. - College of Law - Thi Qar University - Iraq. \\ Email: munirhd@gmail.com
}

\begin{abstract}
The constitutional judiciary, and through his monitoring the constitutionality of laws, is considered one of the best ways by which to ensure the commitment of public authorities in the state to the provisions of the constitution, whether it is judicial or political oversight. The constitutional judiciary has a great position among the authorities of all countries and contemporary constitutional systems. Here it must be said that it is difficult to deny the political nature of constitutional oversight, monitoring the constitutionality of the law is not a purely legal process, nor is it purely political, although it is concerned with the legal text and its inconsistency with the constitution. However, this judiciary is affected by many illegal external factors, the most important of which is the existing political reality. Therefore, we will discuss the concept of constitutional judiciary and the extent of the influence of political reality on the provisions of this judiciary, through the provisions of the judiciary constitutional in some comparative countries, in order to define a set of results and recommendations that were reached them through the research.
\end{abstract}

Keywords: Constitution, Court, Judiciary, Law, Legality. 


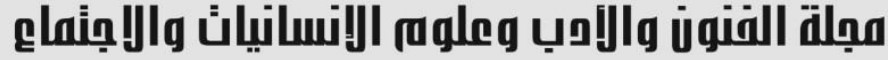

Journal of Arts, Literature, Humanities and Social Sciences

www.jalhss.com

Volume (54) July 2020

العدد (54) يوليو 2020

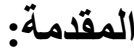

لابد من القول إن رقابة القضاء الدستوري تُعد من أفضل الوسائل التي يمكن من خلالها التأكد من التزام السلطات

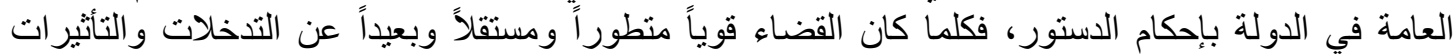

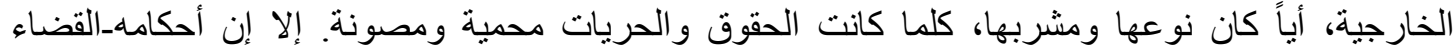

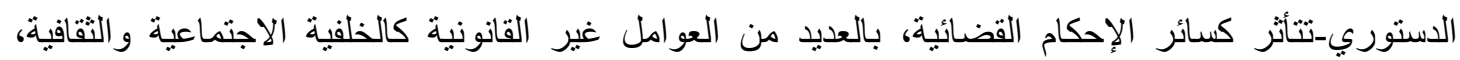

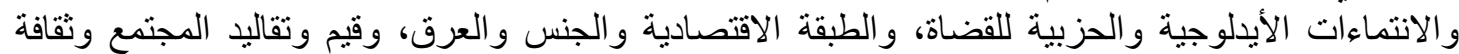

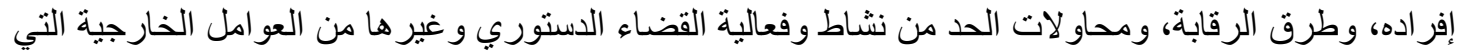

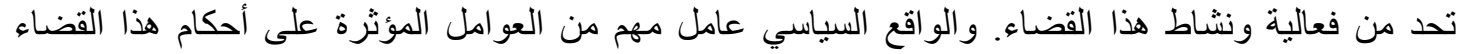

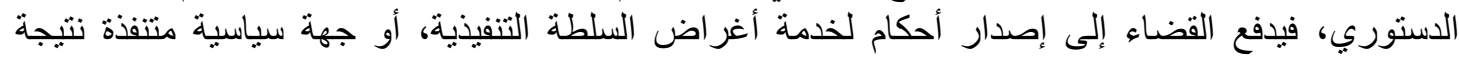

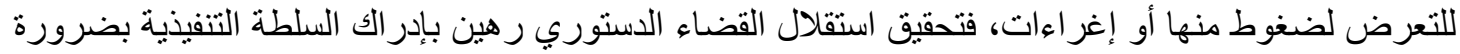

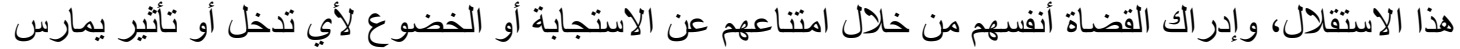
عليهم من أية جهة كانت، وكذلك حرص السلطات العامة في تعزيز هذا الاستقلال.

وتتجسد أهمية الموضوع في إبراز مدى تأثير الواقع السياسي على أحكام القضاء الدستوري، فنجاح الرقابة

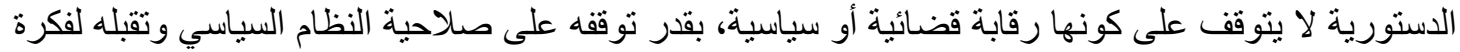

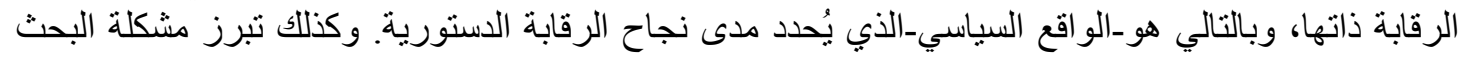

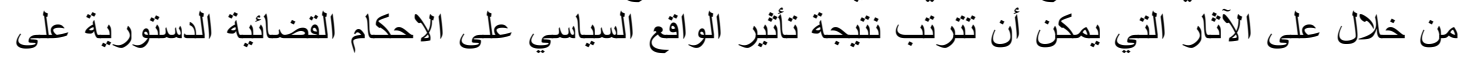

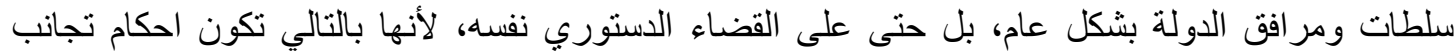

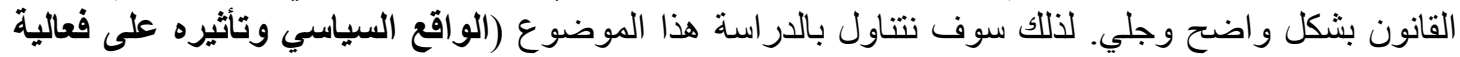

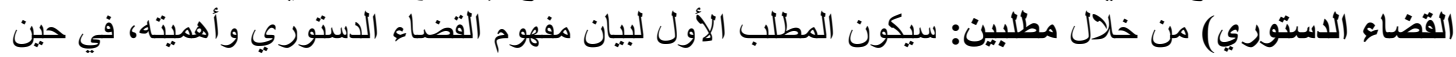
سيكون المطلب الثاني: مدى تأثثر الو اقع السياسي على القئي القضاء الدسنوري.

\section{المطلب الأول: مفهوم القضاء الاستوري واهميته}

لم يعد الدستور مجرد نص سياسي ناتج عن نواق قوى المجتمع ليؤدي دور اً ثانوياً، لكنه أصبح اليوم وثثقة قانونية

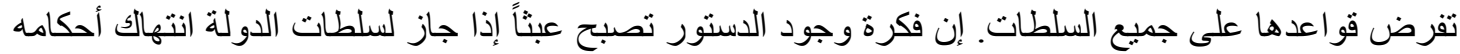

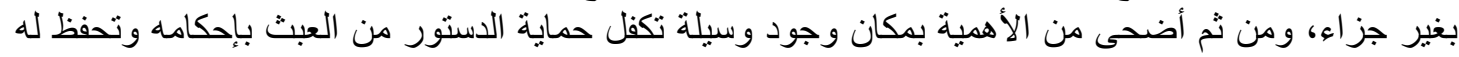

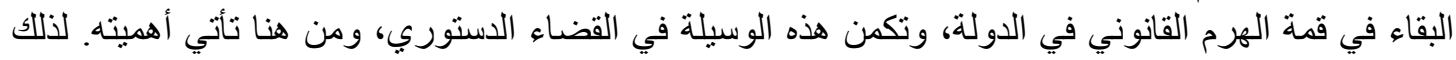

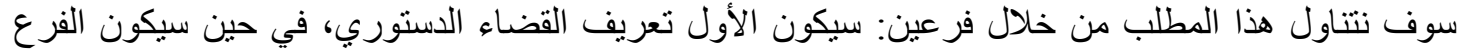
الثناني بيان أهمية هذا القضاء.

الفرع الأول: تعريف القضاء الاستوري: أن الرقابة القضائية على دستورية القو انين سلاح لا يستغنى عنه الفابه

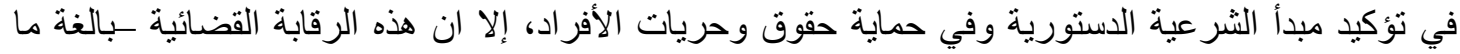

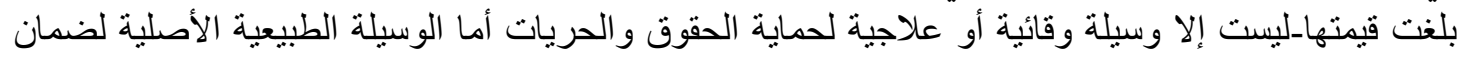

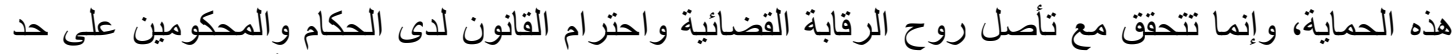

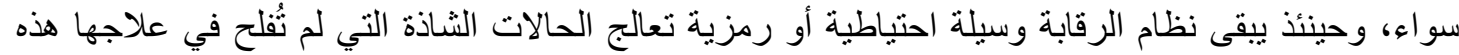

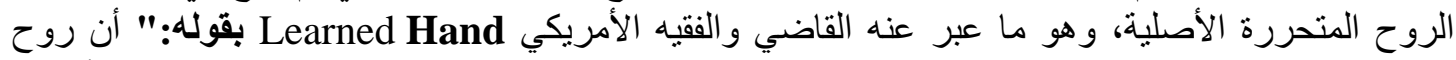

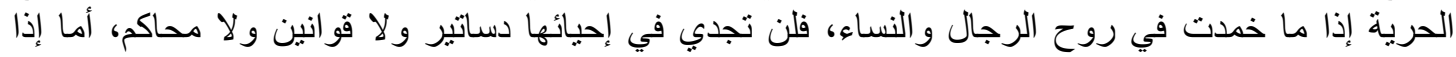

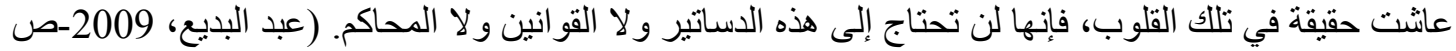




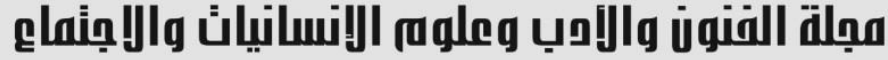

\author{
Journal of Arts, Literature, Humanities and Social Sciences \\ www.jalhss.com \\ Volume (54) July 2020 \\ العدد (54) يوليو 2020
}

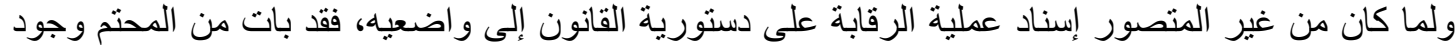

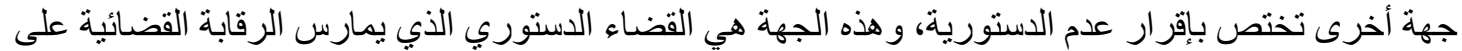

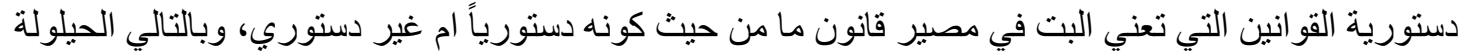

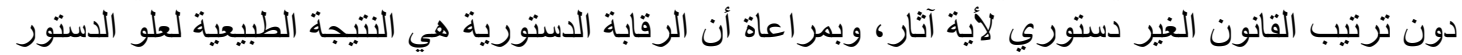

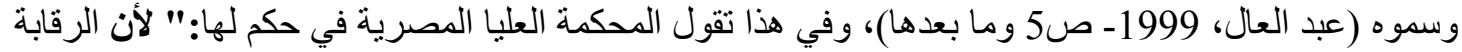

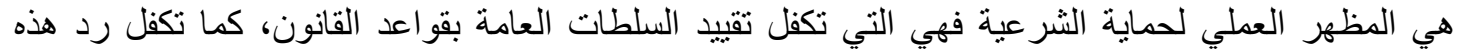
السلطات إلى حدود المشرو عية إن هي تجاوزت تلائك الحدود" (المحكمة العليا، 1976).

ومن المفيد أن نذكر هنا أن القضاء الدستوري يتخذ صوراً مختلفة، فقد تمارس مهام القضاء الدستوري وخاصة

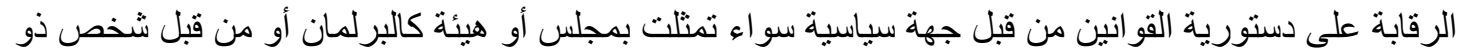

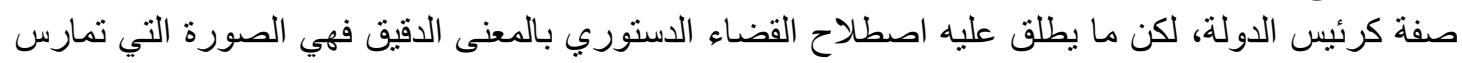

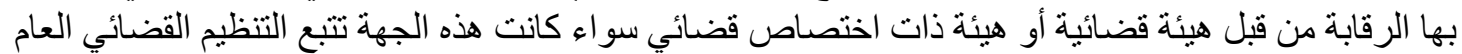

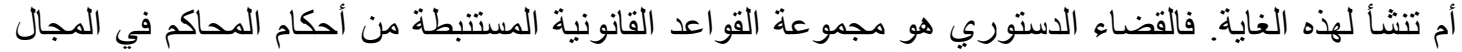

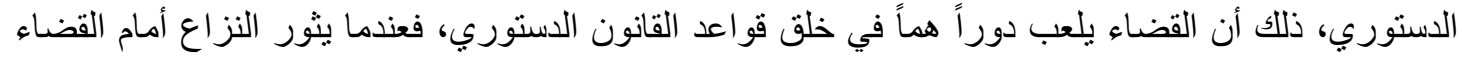

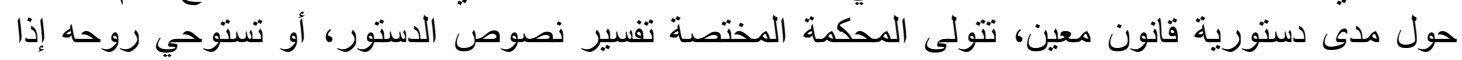
تطلبتها النصوص الصريحة، لتقضي في نهاية المر بدسنورية أو عدم دستورية القانون محل النون النزاع (صليبا،

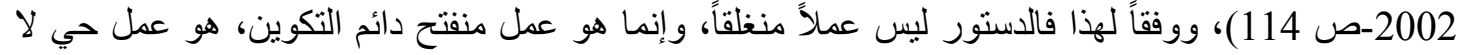

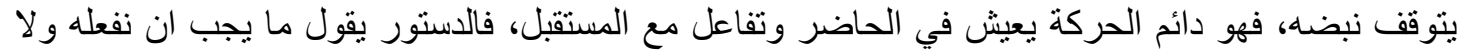

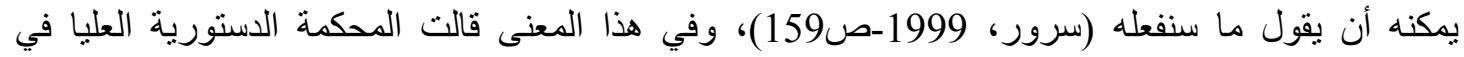

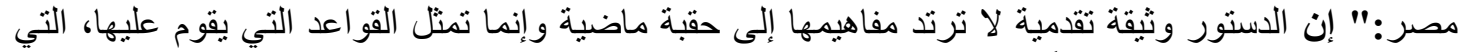

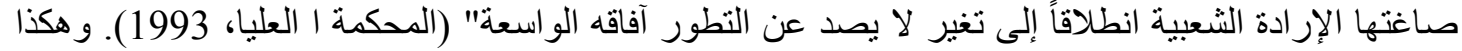

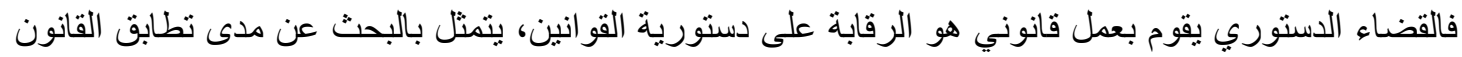

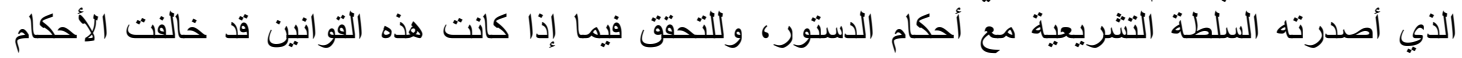

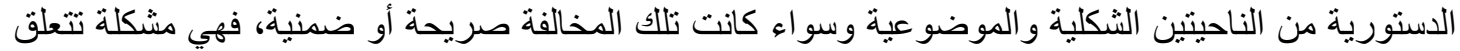

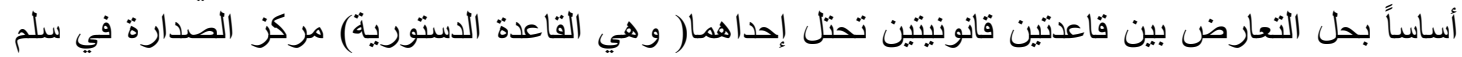

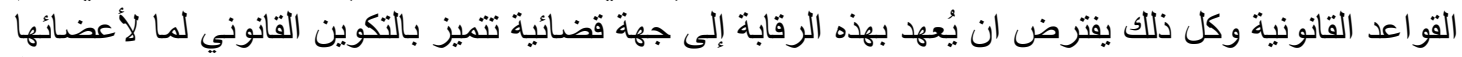

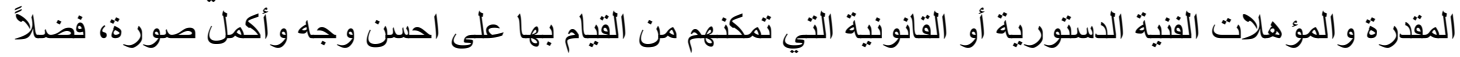

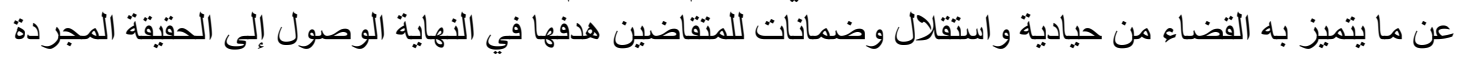

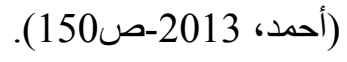

الفرع الثاني: أهمية القضاء الاستوري: تتسم الدساتير المعاصرة في مجمل أحكامها، قواعد تقوم على ألى

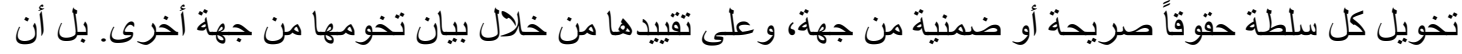

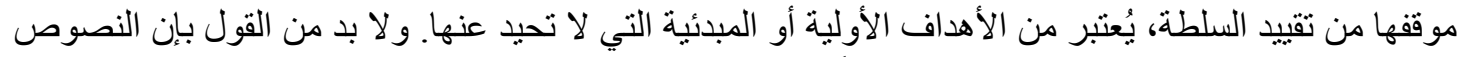

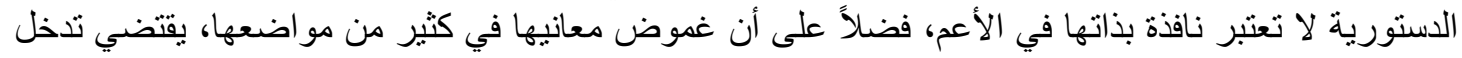

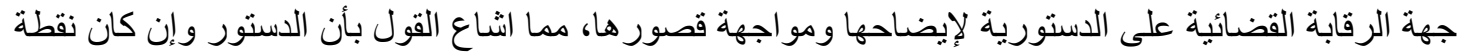

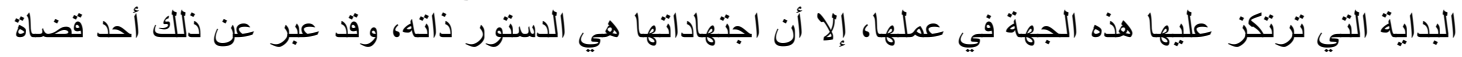

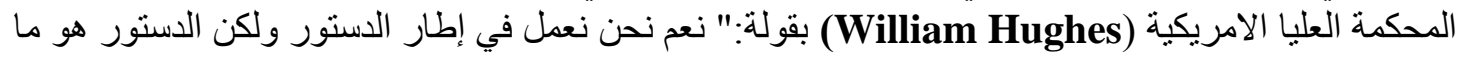

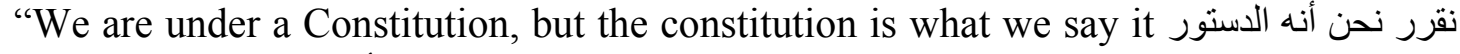
" is".

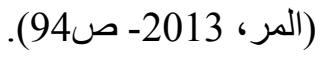




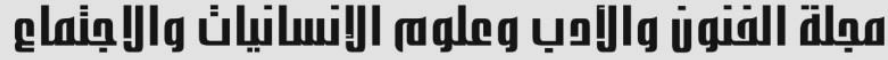

\author{
Journal of Arts, Literature, Humanities and Social Sciences \\ www.jalhss.com \\ Volume (54) July 2020 \\ العدد (54) يوليو 2020
}

وبالتالي أصبحت الحاجة كبيرة وملحة للقضاء الدستوري من أجل تحقيق التوازن بين السلطات العامة في الدولة

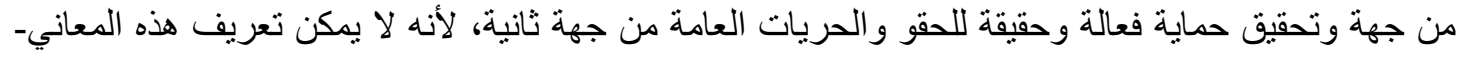

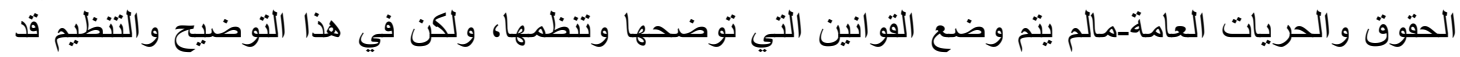

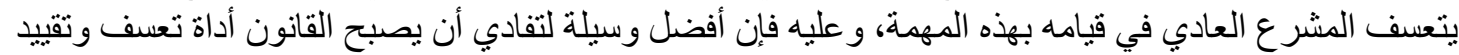

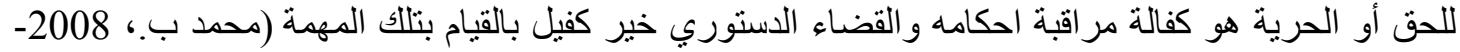

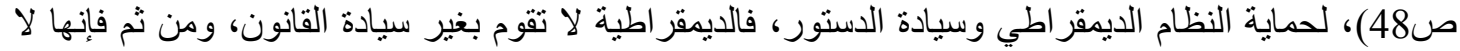

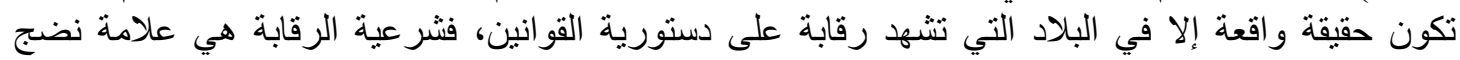

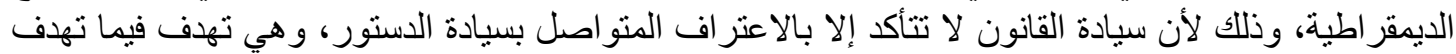

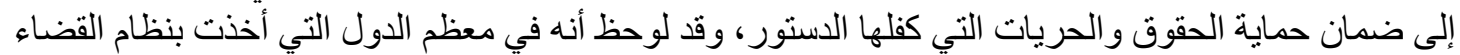

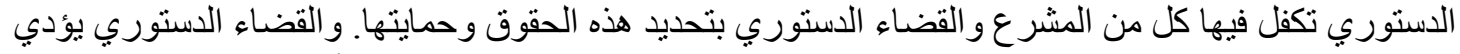

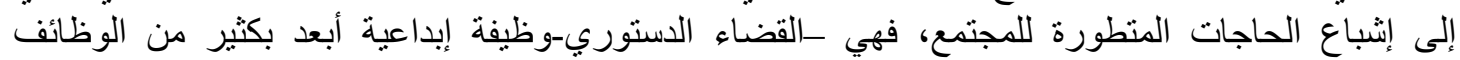

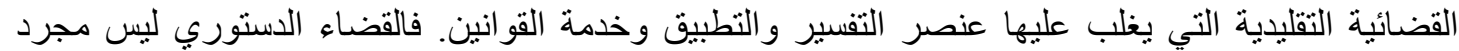

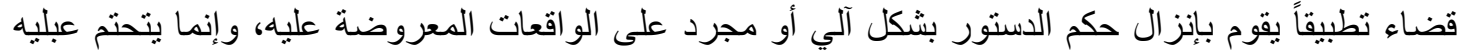

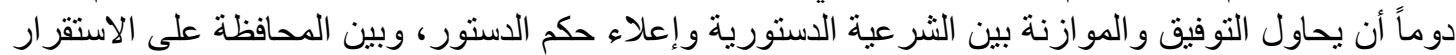

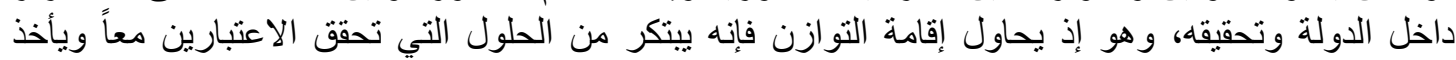

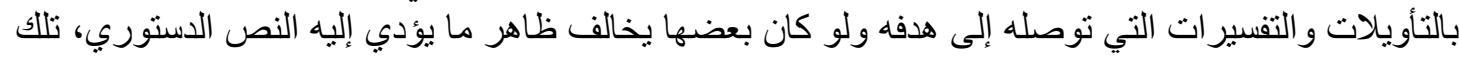

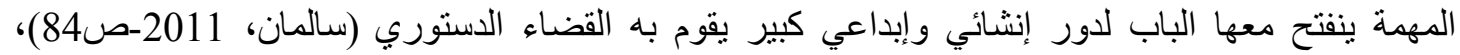

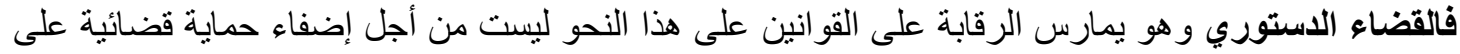

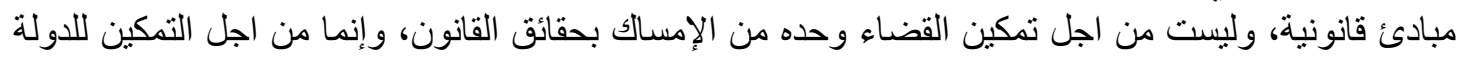

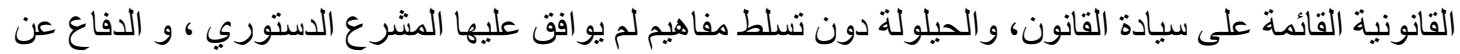

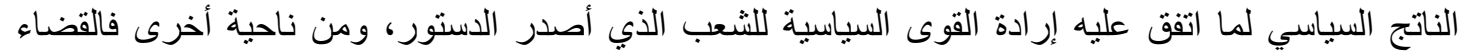

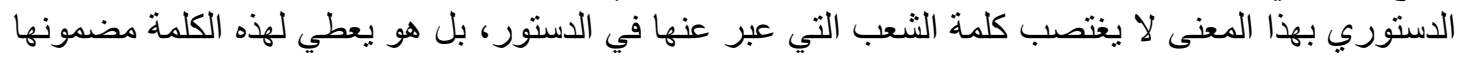

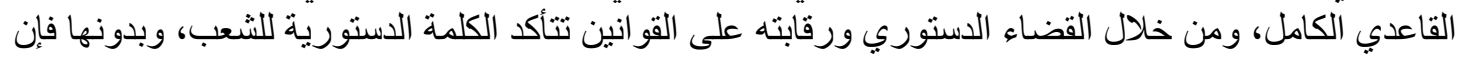
هذه الكلمة الدستورية تضحى بغير مضمون قاعدي وبغير فعالية، وتنحل لكي تصبح كما فال Oliver Cayla

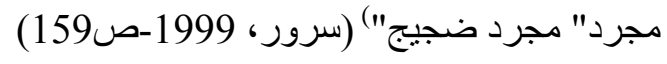

\section{المطلب الثاني: مدى تأثير الواقع السياسي على القضاء الاستوري}

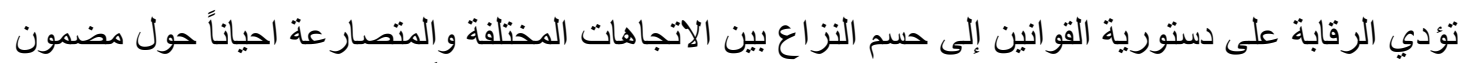

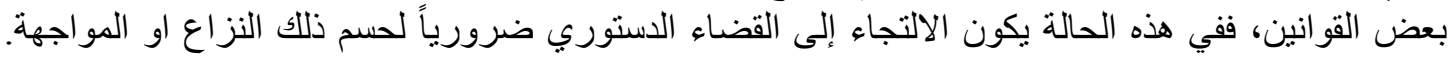

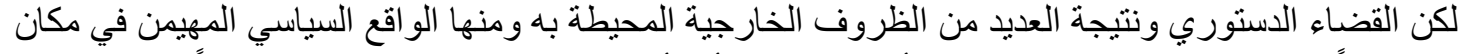

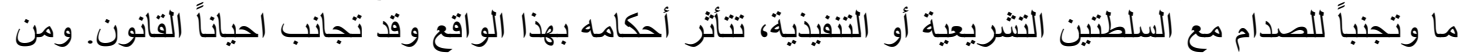

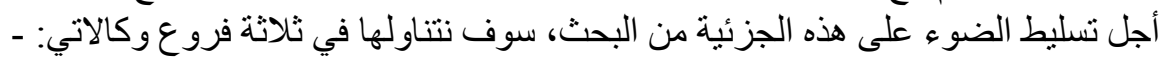

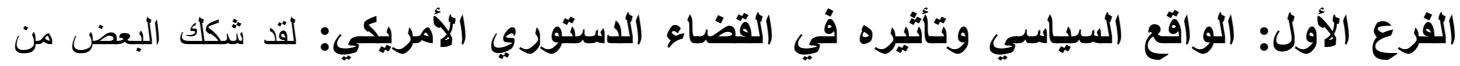

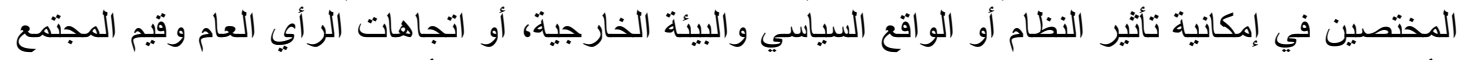

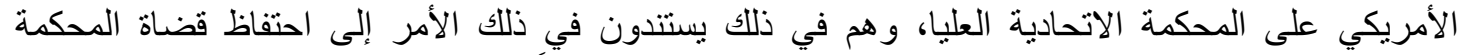

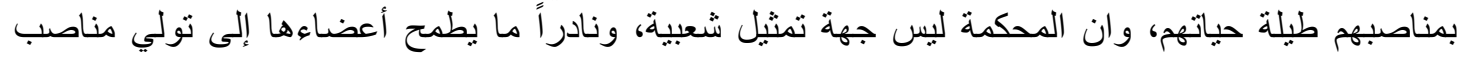

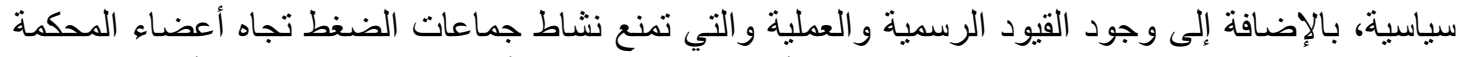

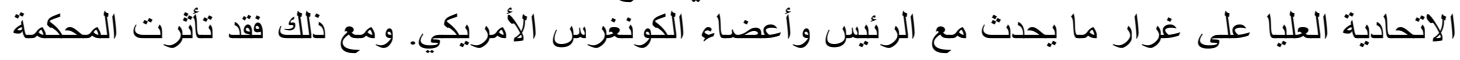




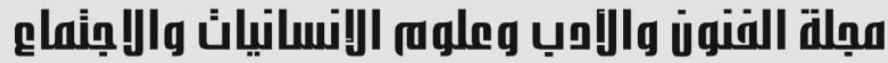

\author{
Journal of Arts, Literature, Humanities and Social Sciences \\ www.jalhss.com \\ Volume (54) July 2020 \\ العدد (54) يوليو 2020
}

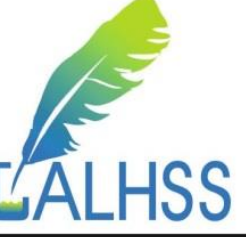

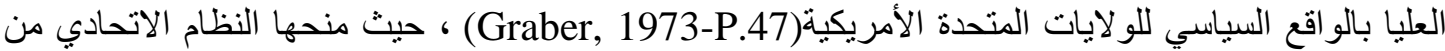

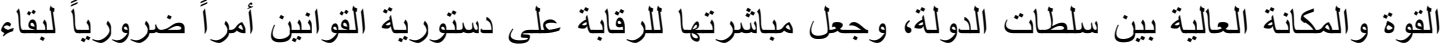

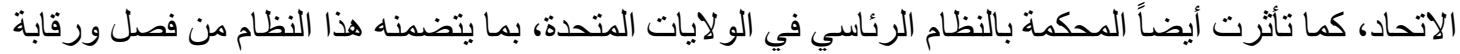

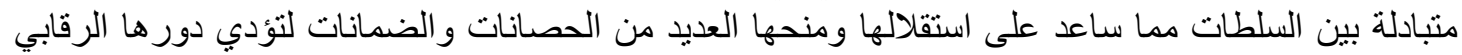

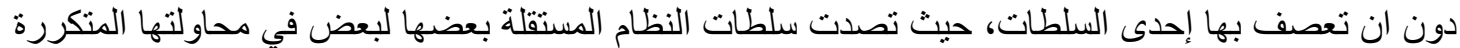

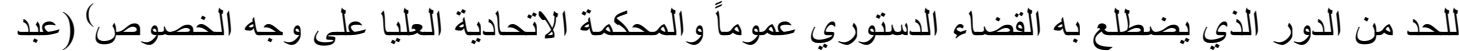

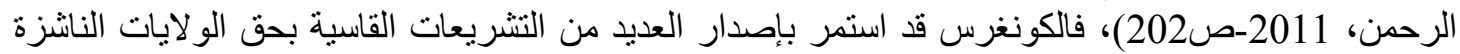

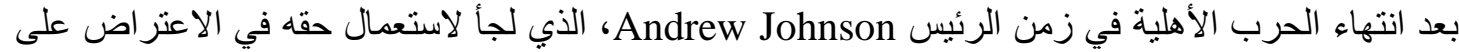

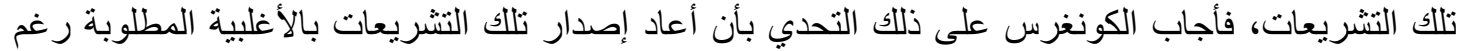

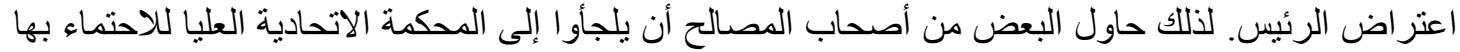

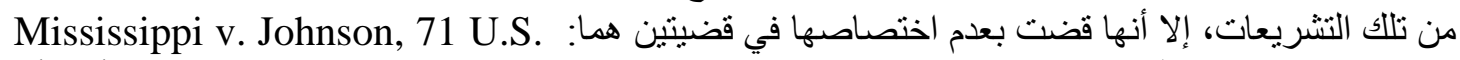
(1866) 475، وقضية (1867) Georgia v. Stanton, 73 U.S. 50 وحاولت المحكمة من جانب أخر أن

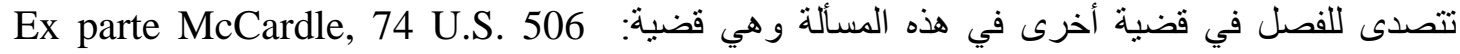

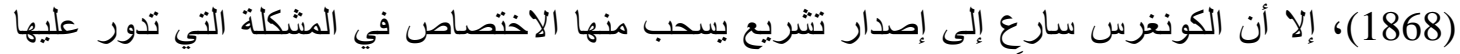

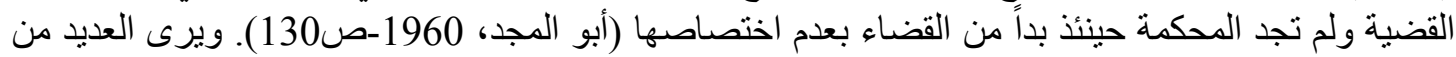

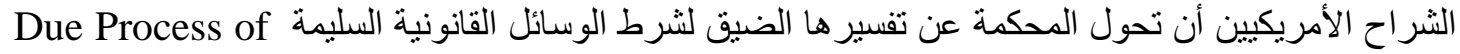

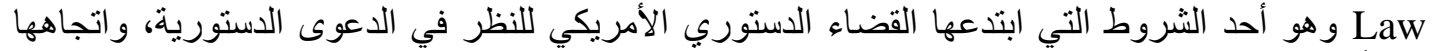

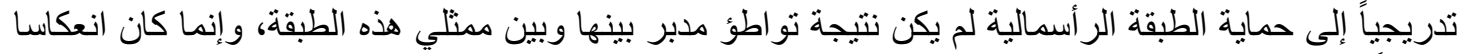

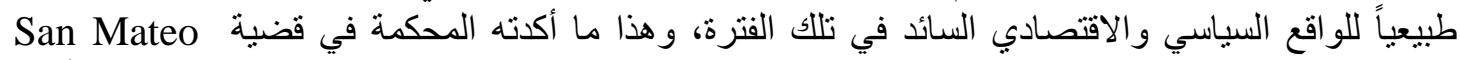

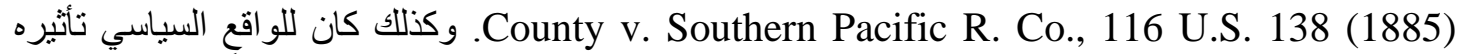

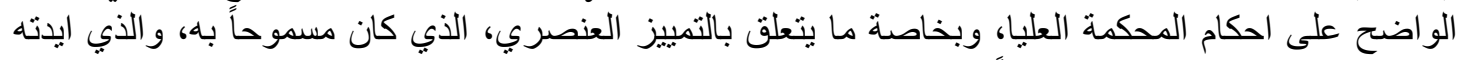

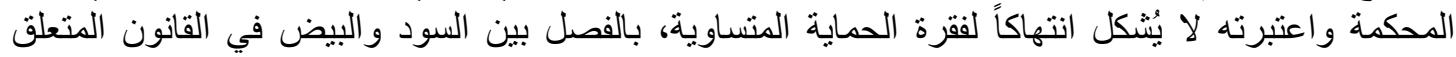

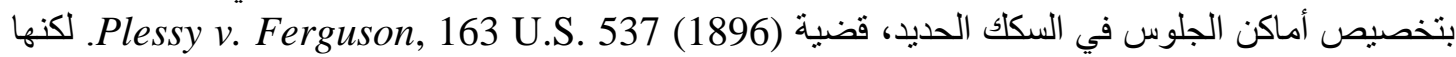

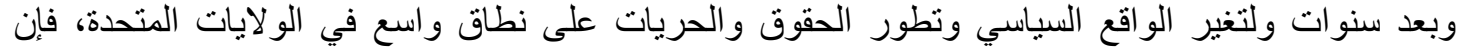

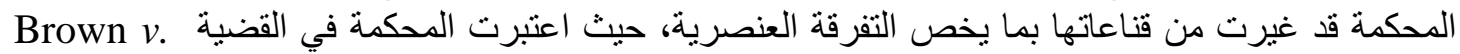
Board of Education of Topeka, 347 U.S. 483 (1954)

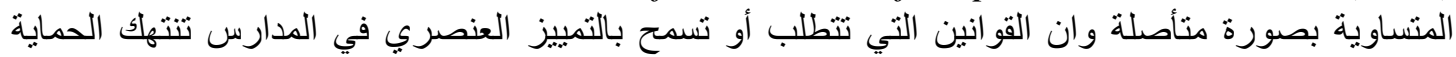

المتساوية)(Schunk, 2006-P.104)

الفرع الثاني: الواقع السياسي وتأثيره في القضاء الاستوري المصري : أن المشرع المصري قد

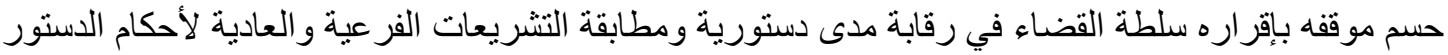

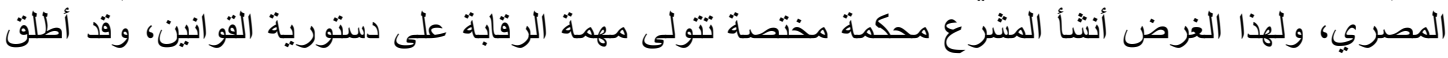

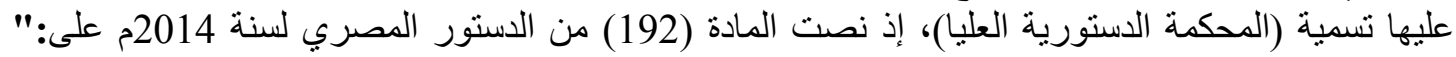

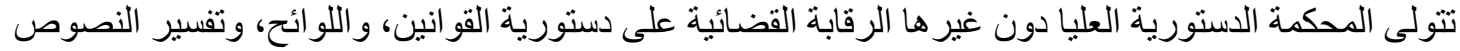

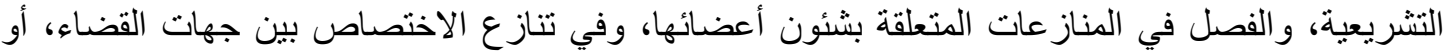

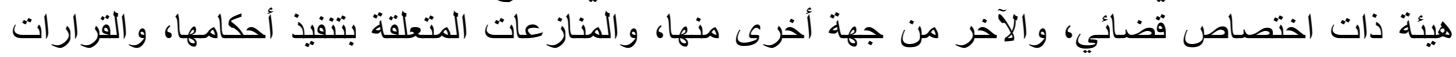

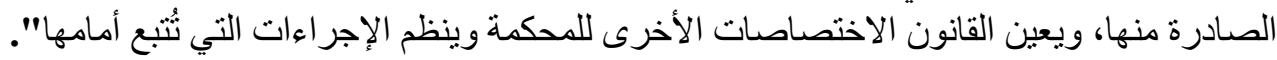

فالو اقع السياسي المصري وما به من اختلال بين السلطات وتناقض بين الرقابة الدستورية، وطموحات السلطة

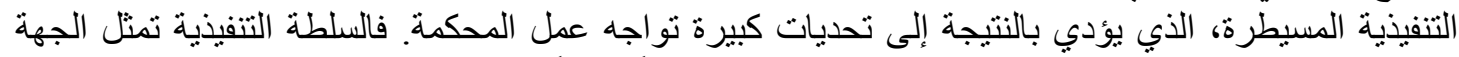

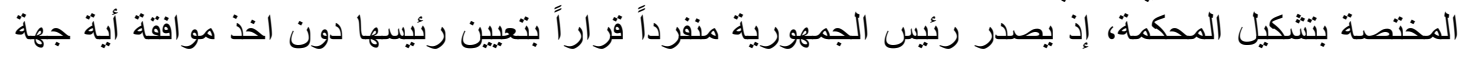
أخرى وله تعيين تعين نائب للرئيس وذلك من بين اثثين نرشح أحدهما الجمعية العامة للمحكمة ويرشح الآخر 


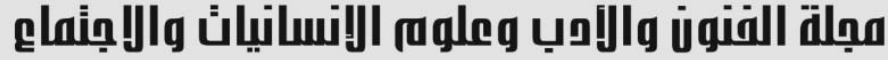

\author{
Journal of Arts, Literature, Humanities and Social Sciences \\ www.jalhss.com \\ Volume (54) July 2020 \\ العدد (54) يوليو 2020
}

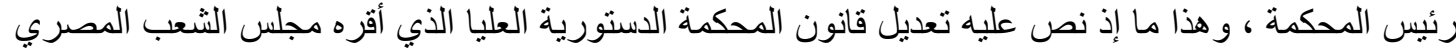

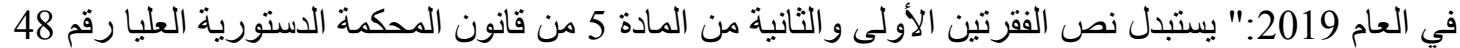

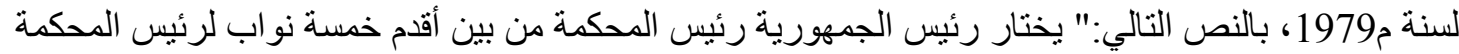

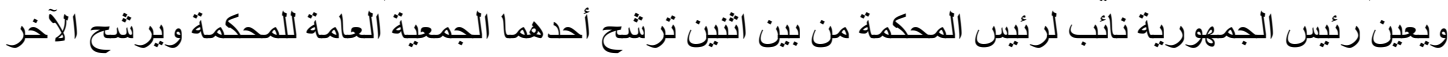

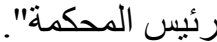

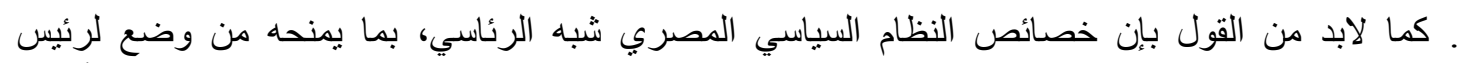

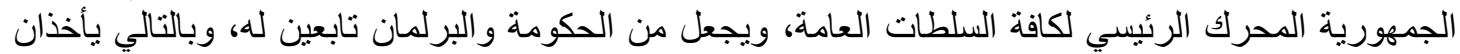

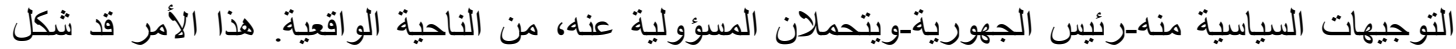

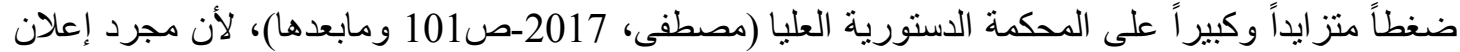

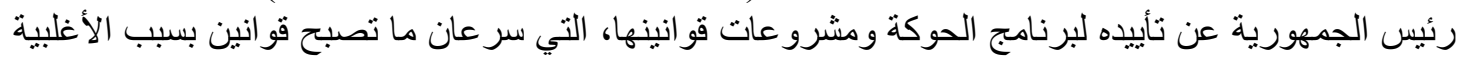

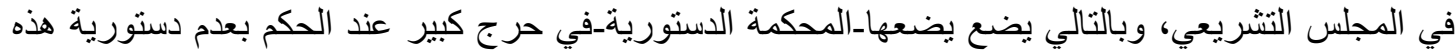

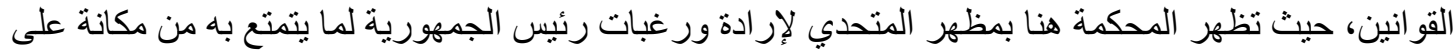

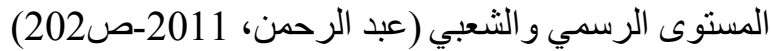

وقد عبرت المحكمة الدستورية العليا عن التزامها بتفسير الدستور، وممارسة رقابتها في إطار منظومة القيم

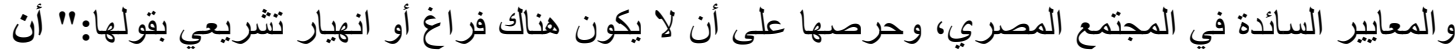

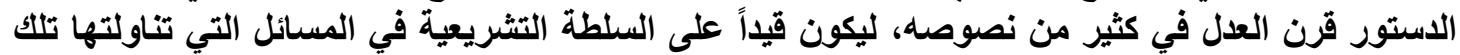

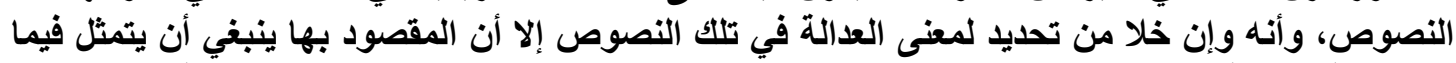

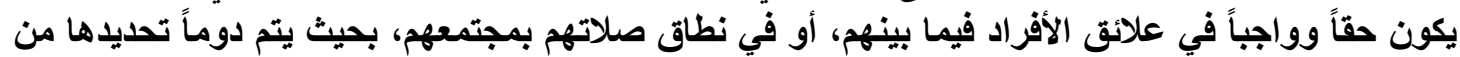

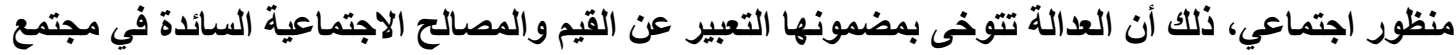

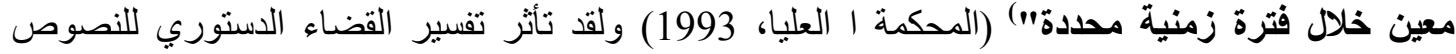

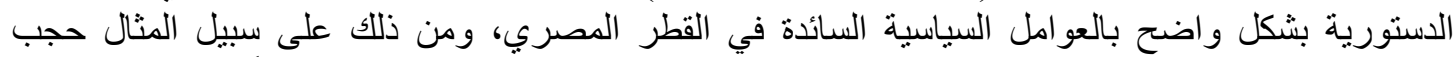
الاختصاص الأصلي بتفسير الدستور عن المحكمة الدستورية العليا، والذي جاء منسجية الدماً نتيجة لسبق نتأثر

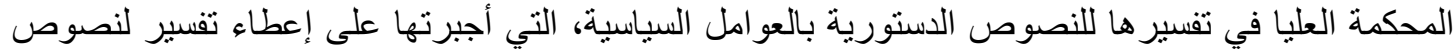

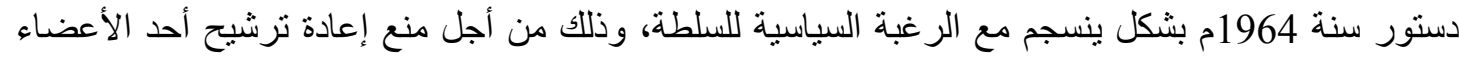

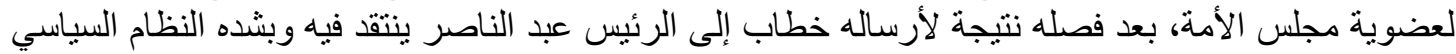

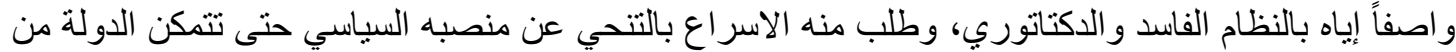

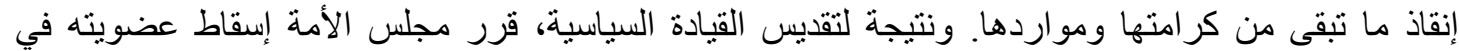

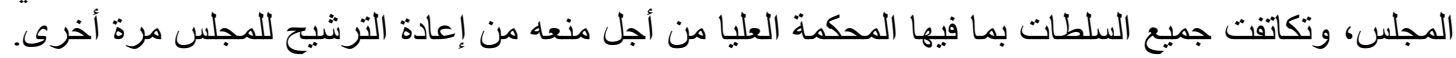

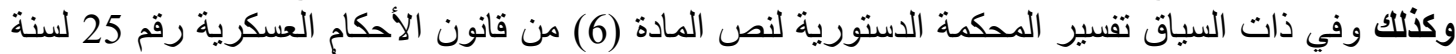

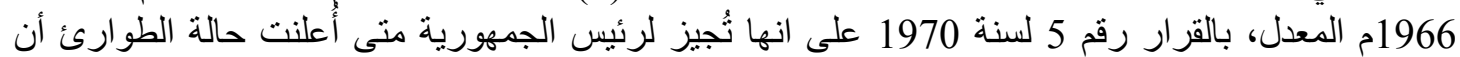

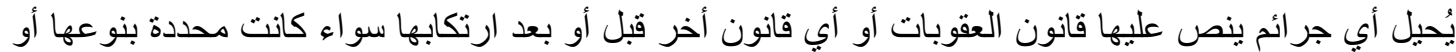

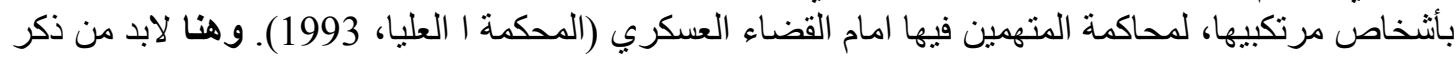

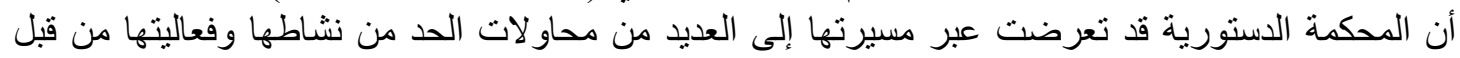

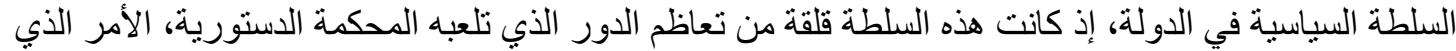

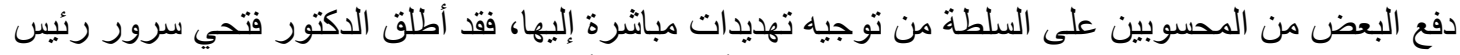

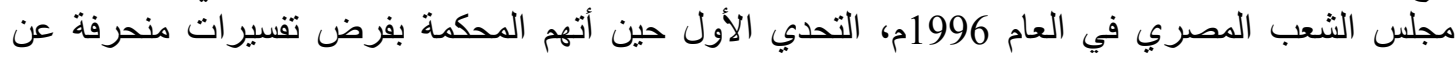

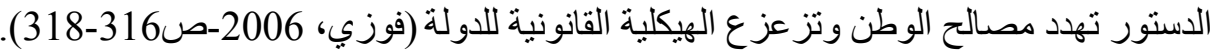




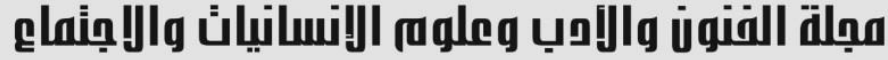

Journal of Arts, Literature, Humanities and Social Sciences www.jalhss.com

الفرع الثالث: الواقع السياسي وتأثيره في القضاء الاستوري العراقي: ان النصوص الستورية الني

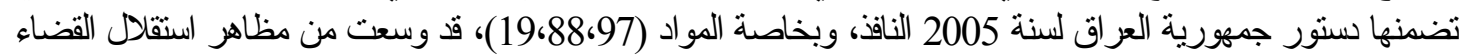

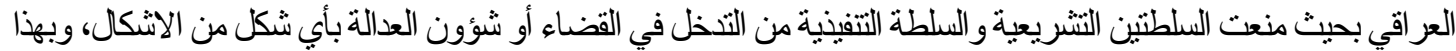

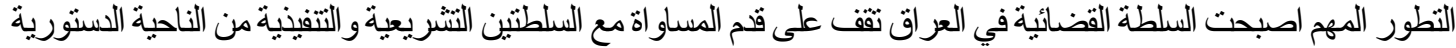
النظرية.

وباعتماد منطق المخالفة، بطالعنا لفظ (الو اقع السياسي أو لفظ النسييس) كنقيض موضو عي لاستقلال القضاء وضمان حيادتيه

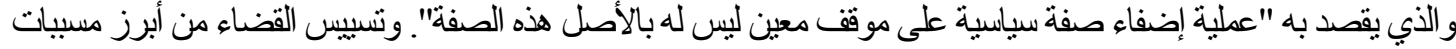

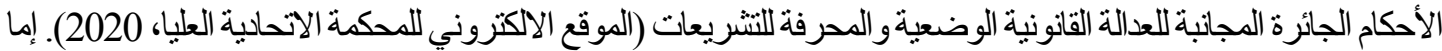
فيما يتعلق بنتكيل المحكمة الاتحادية العليا على وفق سلتور جمهورية العراق لسنة لعام 2005 النافذ، فقد أثنارت المادة (92/ثانثانياً

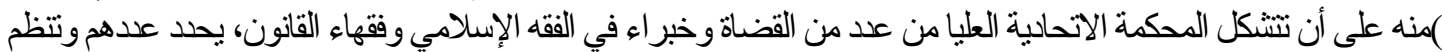

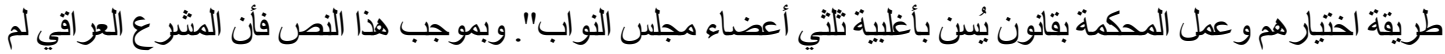

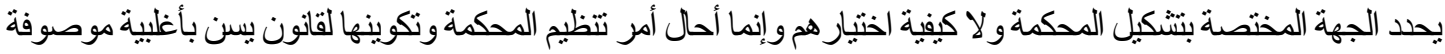

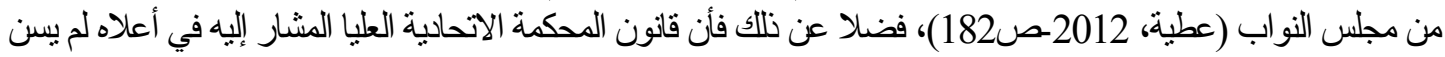

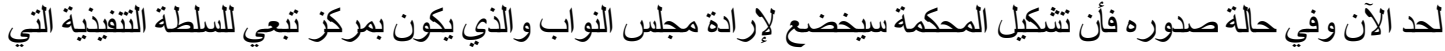

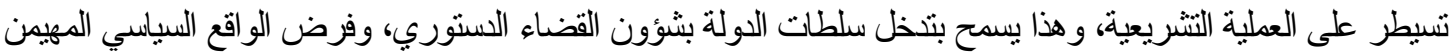

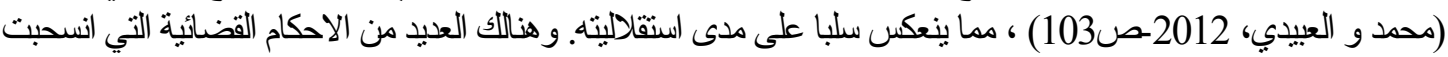

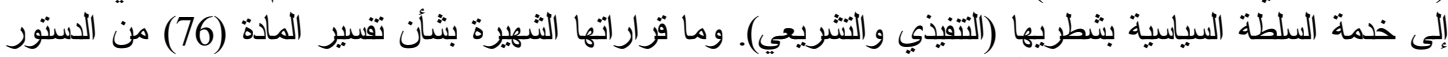

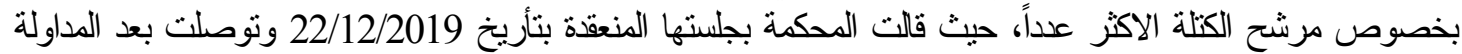

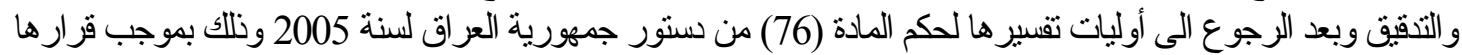

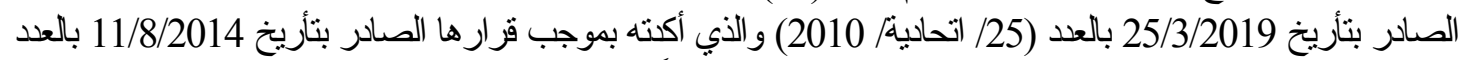

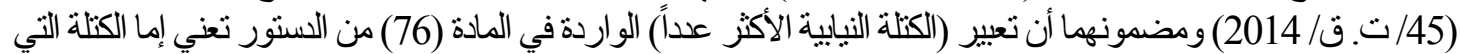

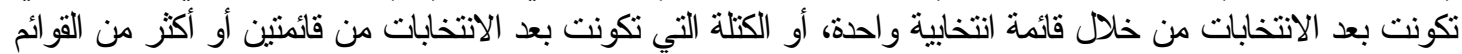

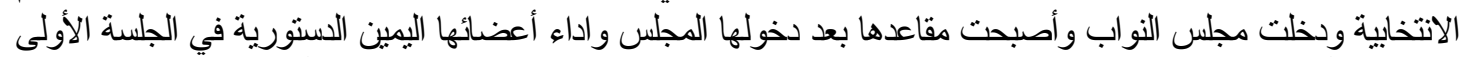

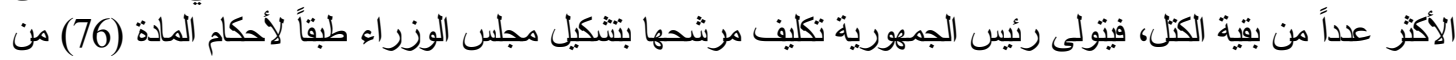

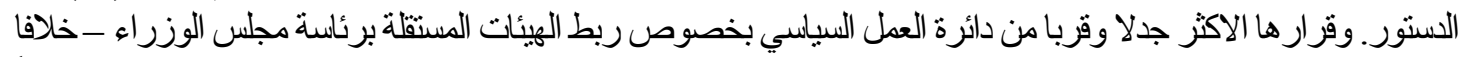

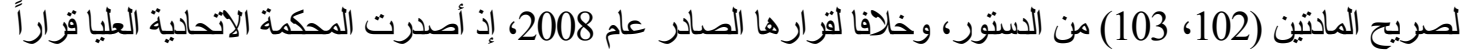

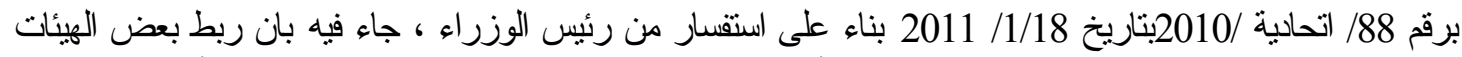

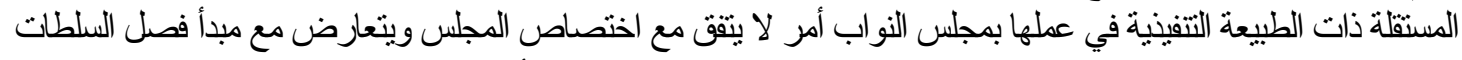

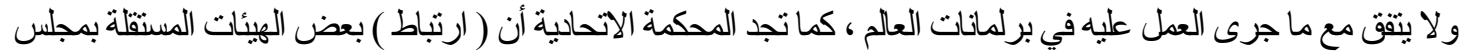

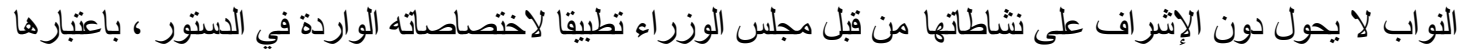

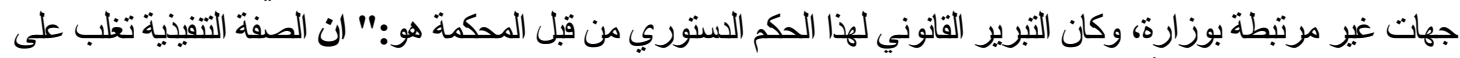

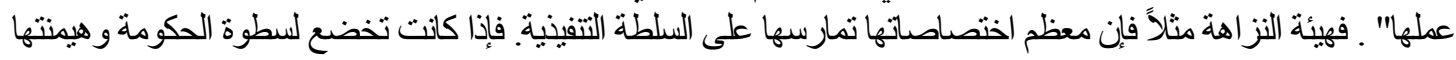

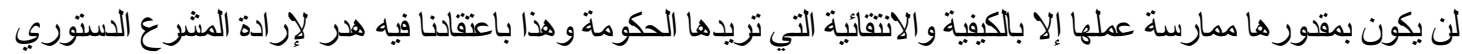

في إنثاء هذه الهيئات المستقلة.

وكتلك قرار هاـالمكمة الاتحاديةفي القضية رقم 12/اتحادية/2018، حيث قالت المحكمة: "ان الطعن الذي اثاره المدعي في

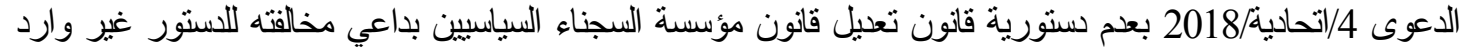

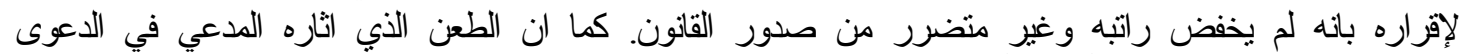

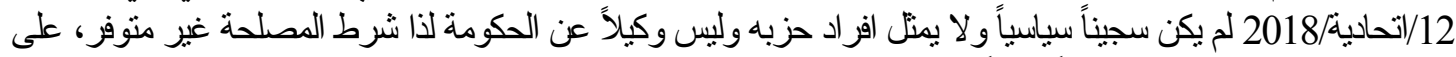

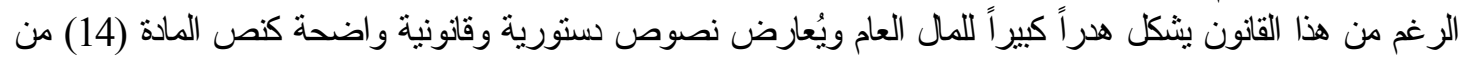

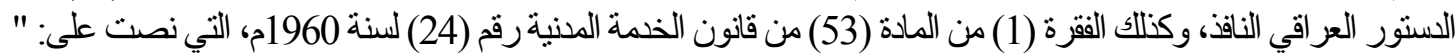




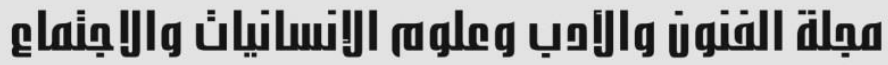

Journal of Arts, Literature, Humanities and Social Sciences www.jalhss.com

لا يحق للموظف ان يتقاضى راتيين عن وظيفتين في آن واحد"، وكنلك البنذ (11) من المادة (21) من قانون النقاعد الموحد رقم

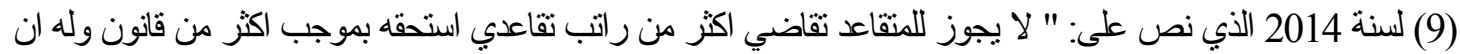

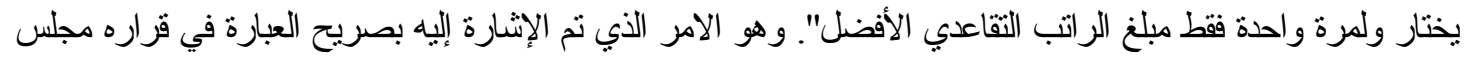
شورى الدولة رقم 2014/39 والصادر في 2014/4/6 (الموقع الالكتروني للمحكمة الاتحادية العليا، 2020).

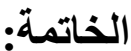

من خلال ما تقدم من البحث، نستطيع أن نوجز أهم النتائج والتوصيات التي توصل إليها البحث، وهي كالاتي:

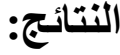

1. للقضاء الدستوري دوراً مهماً و أساسياً في حماية الحقوق و الحريات العامة من خلال ممارسته الرقابة

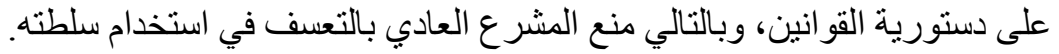
2. القضاء الدستوري لا يغتصب كلمة الثعب التي عبر عنها في الدستور، بل هو يعطي لهذه الكلمة

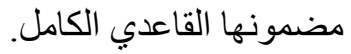
3. هناك العديد من ألعو امل الخارجية الغير قانونية التي تؤثر على القضاء الدستوري وأحكامه، ويُعتبر

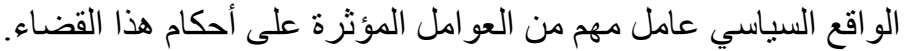

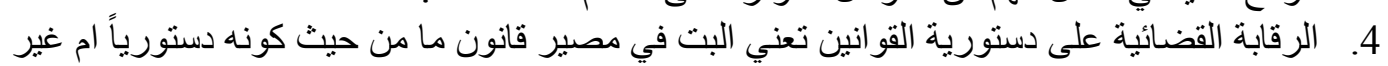
داستوري. 5. الدستور ليس عملاً منظلقاً، وإنما هو عمل منفتح دائم التكوين، هو عمل حي لا يتوقف نبضه، فهو دائم الحركة يعيش في الحاضر وتفاعل مع المستقبل.

1. يجب أن يكون هناك المزيد من الضمانات التي تحمي القضاء الدستوري وتجعله بعيداً عن الصر اعات التهات

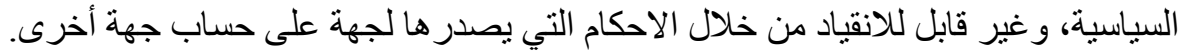

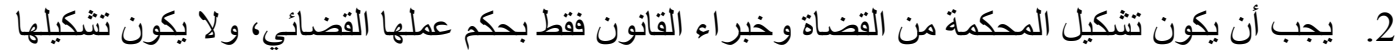

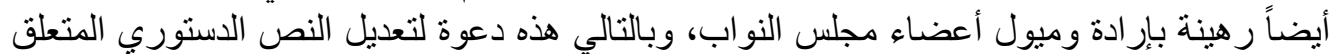

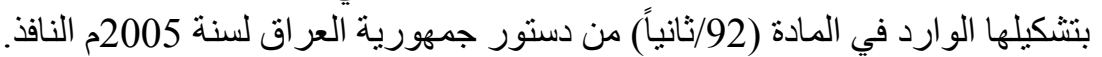

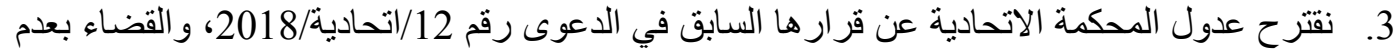
دستورية قانون رقم (35) لسنة 2013 قانون التعديل الأول لقانون مؤسسة السجناء السياسيين رقم

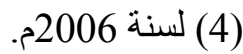




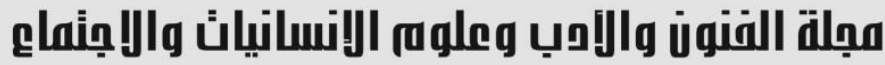

Journal of Arts, Literature, Humanities and Social Sciences

www.jalhss.com

Volume (54) July 2020

العدد (54) يوليو 2020

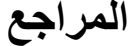

1. Graber, M. (1973-P.47). The Nonmajoritarian Difficulty Legislative Defence to the Judiciary. New York: american Political Studies.

2. Schunk, P. (2006-P.104). Meditation of a Militant Moderate. Exford: Rowman \& Littlefield.

$$
\begin{aligned}
& \text { 3. أحمد فتحي سرور. (1999-ص159). الحماية الدستورية للحقوق والحريات. القاهرة: دار الثروق. } \\
& \text { 4. أحمد كمال أبو المجد. (1960-صنا130). الرقابةعلى دستورية القوانبن. القاهرة: دار النهضة العربية. } \\
& \text { 5. المحكمة ا العليا، } 21 \text { لسنة } 25 \text { قضائية دستورية (يونيو 30، 1993). } \\
& \text { 6. المحكمة العليا، } 11 \text { (لسنة } 5 \text { دسنورية قضائية } 3 \text { ابريل، 1976). } \\
& \text { 7. الموقع الاكتروني للدحكمة الاتحادية العليا. (22 6، 2020). تم الاسترداد من } \\
& \text { https://www.iraqfsc.iq/searchkrar.php } \\
& \text { 8. أمين محمد صليبا. (2002-ص 114). دور القضاء الدستوري في إرساء دولة القانون. بيروت: المؤسسة }
\end{aligned}
$$

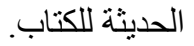

$$
\begin{aligned}
& \text { 9. باسل عبد الله محمد. (2008-ص48). دور القضاء الدستوري في تطوير مفهوم الحقوق والحريات. الأردن: } \\
& \text { جامعة آل البيت. } \\
& \text { السياسة الدصرية. بيروت: دار تدوين للطباعة و النشر. } \\
& \text { 11. ثروت عبد العال. (1999- ص5 وما بعدها). حدود رقابة المشروعية والملائمة في قضاء الدستورية. القاهرة: } \\
& \text { دار النهضة العربية. } \\
& \text { 12. عاطف سالم عبد الرحمن. (2011-صارئ202). دور القضاء الدستوري في الأصلاح السياسي والاجتماعي } \\
& \text { والاقتصادي. القاهرة: دار النهضة العربية. } \\
& \text { 13. عبد العزيز محمد سالمان. (2011-ص484). ضو/بطوقيود الرقابة الدستورية . مصر : سعد سكك للمطبو عات } \\
& \text { القانونية. } \\
& \text { 14. عبد محمد، و سعيل العبيدي. (2012-صاصنيع). استقلال القضاء في التثريع العراقي النافذ. بغداد: مكتبة } \\
& \text { الصباح للنشر و التوزيع. } \\
& \text { تفسير الدستور العراقي. بيروت: منشور ات زين الحقوبة العقية. }
\end{aligned}
$$




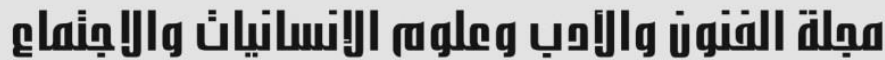

Journal of Arts, Literature, Humanities and Social Sciences

www.jalhss.com

Volume (54) July 2020

العدد (54) يوليو 2020

\section{References}

1. Graber, M. (1973-P.47). The Nonmajoritarian Difficulty Legislative Defense to the Judiciary. New York: american Political Studies.

2. Schunk, P. (2006-P.104). Meditation of a Militant Moderate. Exford: Rowman \& Littlefield.

3. Ahmed Fathi Sorour. (1999-p. 159). Constitutional protection of rights and freedoms. Cairo: Dar Al Shorouk.

4. Ahmed Kamal Abu Al-Majd. (1960-p. 130). Control the constitutionality of laws. Cairo: Arab Renaissance House.

5. The Supreme Court, 21 for the 25th year in constitutional jurisdiction (June 30, 1993).

6. Supreme Court, 11 (for the year 5 constitutional constitution April 3, 1976).

7. The website of the Federal Supreme Court. (22 6, 2020). Retrieved from https://www.iraqfsc.iq/searchkrar.php

8. Amin Muhammad Saliba. (2002-p. 114). The role of the constitutional judiciary in establishing a state of law. Beirut: Modern Book Corporation.

9. Basil Abdullah Mohammed. (2008-p. 48). The role of the constitutional judiciary in developing the concept of rights and freedoms. Jordan: Al Al-Bayt University.

10. Tamer Mostafa. (2017-p. 101 and beyond). The Struggle over Constitutional Power - The Role of the Supreme Constitutional Court in Egyptian Politics. Beirut: Blogging House for Printing and Publishing.

11. Tharwat Abdel-Al. (1999- p. 5 and beyond). The limits of legal and appropriate control in the constitutional jurisdiction. Cairo: Arab Renaissance House.

12. Atef Salem Abdel-Rahman. (2011-p. 202). The role of the constitutional judiciary in political, social and economic reform. Cairo: Arab Renaissance House.

13. Abdul Aziz Muhammad Salman. (2011- p. 84). Constitutional controls and restrictions. Egypt: Saad Samak for Legal Publications.

14. Abdul Muhammad, and Suhail al-Obeidi. (2012-p. 103). Independence of the judiciary in the Iraqi legislation in force. Baghdad: Al-Sabah Library for Publishing and Distribution.

15. Essam Saeed Abdul Ahmed. (2013-p. 150). Control over the constitutionality of laws. Beirut: Modern Book Corporation.

16. Ali Hadi Attia. (2012-p. 182). The general theory in the interpretation of the constitution and the directions of the Supreme Federal Court in the interpretation of the Iraqi constitution. Beirut: Zain Human Rights Publications. 


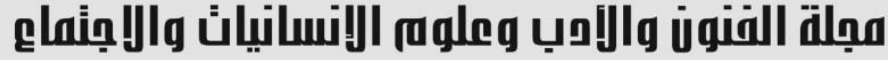

Journal of Arts, Literature, Humanities and Social Sciences

www.jalhss.com

17. Awad al-Murr. (2013- p. 94). Control the constitutionality of laws in their main features. Cairo: Rene-Jean Deboy Center.

18. Mohamed Salah Abdel-Badi. (2009-p. 19). Constitutional protection of public freedoms between the legislature and the judiciary. Cairo: Arab Renaissance House. 19. Hisham Fawzy. (2006-pp. 316-318). Constitutional oversight of laws between America and Egypt. Cairo: Arab Renaissance House. 